\title{
RELATIONSHIP BETWEEN PSYCHOSOCIAL STRESS AND MENSTRUAL FUNCTION-RELATED ABNORMALITIES AMONG THE FEMALE UNDERGRADUATE MEDICAL STUDENTS
}

\author{
Rolinda Rajkumari1 ${ }^{1}$ Susie Keithellakpam², Joshna Thiyam³, N. Minita Devi4
}

${ }^{1}$ Associate Professor, Department of Physiology, Jawaharlal Nehru Institute of Medical Sciences, Porompat, Imphal-East, Manipur. ${ }^{2}$ Assistant Professor, Department of Physiology, Jawaharlal Nehru Institute of Medical Sciences, Porompat, Imphal-East, Manipur. ${ }^{3}$ Assistant Professor, Department of Physiology, Jawaharlal Nehru Institute of Medical Sciences, Porompat, Imphal-East, Manipur. ${ }^{4}$ Assistant Professor, Department of Community Medicine, Jawaharlal Nehru Institute of Medical Sciences, Porompat, Imphal- East, Manipur.

\section{ABSTRACT}

\section{BACKGROUND}

Several studies have shown contradictory results as some of the studies reported the association between stress score and menstrual function-related abnormalities while some have failed to show any relationship between stress score and menstrual function-related abnormalities. Hence, this study was conducted with an aim to see whether there is any relationship between psychosocial stress as measured by Inventory to Measure Psychosocial Stress (IMPS) and menstrual function-related abnormalities among the female undergraduate medical students.

\section{MATERIALS AND METHODS}

This study was conducted on 81 female undergraduate students of a Medical college. A questionnaire along with the IMPS was provided to the students. The questionnaire dealt with anthropometric data, menstrual history and menstrual health status.

\section{RESULTS}

Fifty-three percent (53\%) of students have stress score ranging from 20-39 while 47\% have stress score 10-19. A majority of students $(80 \%)$ reported premenstrual symptoms. The proportion of students who reported irregular menstrual cycles and heavy menstrual flow were $67 \%$ and $62 \%$ respectively. Most of the students (80\%) also reported menstrual pain. The students who have premenstrual symptoms have significantly higher stress score than those who do not $(\mathrm{p}<0.001)$. Those students who reported menstrual pain $(\mathrm{p}<0.001)$ and irregular menstrual cycle $(\mathrm{p}<0.001)$ also have significantly higher stress score than those who do not. Logistic regression showed that stress was the significant predictor of premenstrual symptoms $(\mathrm{p}=0.001)$ and menstrual pain $(p=0.001)$. Both stress score $(p=001)$ and body mass index $(p=0.01)$ were found to be predictors for experiencing irregular menstrual cycle.

\section{CONCLUSION}

Our study showed that students who reported menstrual-related abnormalities had higher stress score than those who did not. Also stress score is an independent predictor of menstrual-related abnormalities.

\section{KEYWORDS}

Psychosocial Stress, IMPS, Premenstrual Symptoms, Menstrual Pain.

HOW TO CITE THIS ARTICLE: Rajkumari R, Keithellakpam S, Thiyam J, et al. Relationship between psychosocial stress and menstrual function-related abnormalities among the female undergraduate medical students. J. Evolution Med. Dent. Sci. 2017;6(38):3103-3107, DOI: 10.14260/Jemds/2017/669

\section{BACKGROUND}

Stress is the "wear and tear" our bodies experience as we adjust to our continually changing environment. It has physical and emotional effects which can create positive or negative influence on the individual. As a positive influence, stress can motivate a person for completion of a particular work. As a negative influence, it can bring about feelings of distrust, rejection, anger, and depression, which in turn can cause health problems like headache, heart diseases and stroke.

Financial or Other, Competing Interest: None.

Submission 04-04-2017, Peer Review 01-05-2017,

Acceptance 06-05-2017, Published 11-05-2017.

Corresponding Author:

Dr. Rolinda Rajkumari,

Associate Professor,

Jawaharlal Nehru Institute of Medical Sciences,

Porompat, Imphal-East,

Manipur-795005.

E-mail: rolinda_rk65@rediffmail.com

DOI: $10.14260 /$ jemds/2017/669

\section{(c) $(7)$}

Psychosocial stress is defined as accumulation of stress response leading to physical, psychological and behavioural change. ${ }^{1}$ A previous study conducted in USA reported a nationwide increase in stress among undergraduate college students in various fields of study. ${ }^{2}$ A study on the possible causes of academic stress done on 675 undergraduate students found that examination and examination results were the highest causes of stress, followed by studying for exams and too much to learn within a limited period. ${ }^{3}$

Medical students, in particular, are known to suffer from greater levels of stress due to their heavier academic burdens. The estimated prevalence of stress found in different studies on medical students was higher than that in general population. Prevalence of emotional disorder of $42.6 \%$ was found among medical students in a Malaysian private medical school.4 Study done among 558 medical students in Nepal has shown that the prevalence of stress was $27 \% .{ }^{5}$ Another study conducted in Odisha, India revealed that $53 \%$ of medical students were suffering from stress. In addition, they also reported female students have higher stress score as compared to their male counterparts. ${ }^{6}$ 
The spectrum of menstrual disorder/irregularity ranges from disorder of cycle length to disorder of flow which includes premenstrual syndrome (PMS), painful menstruation (Dysmenorrhoea), absence of menstruation, light, infrequent or delayed flow (Oligomenorrhoea) and excessive or prolonged flow (Menorrhagia). Normal menstrual cycle can be interfered by a number of conditions such as sudden weight loss, over-exercising, medical conditions and even stress. Previous studies among the Japanese workers have shown irregular menstrual cycle at $17.1 \%$. They also reported stress as one of the factors affecting irregular menstrual cycle. ${ }^{7}$

Harlow et al have examined 166 college women, aged 1719 years and shown stress as one of the key factors responsible for menstrual irregularities. ${ }^{8}$ Another study by Ekpenyong et $\mathrm{al}^{9}$ reported that prevalence rate of menstrual disorders was $34.6 \%$ among female undergraduate students in College of Health Sciences, Nigeria. They also found association between academic stress and menstrual disorder. Singh et al found that medical students in India perceived above average or higher level of stress; and a strong association between stress and premenstrual symptoms was observed. ${ }^{10}$ However, Sood et al found no clear association between stress and menstrual abnormality. ${ }^{11}$

Hence, this study was conducted with an aim to see whether there is any relationship between psychosocial stress as measured by Inventory to Measure Psychosocial Stress (IMPS) and menstrual function-related abnormalities among the female undergraduate medical students.

\section{MATERIALS AND METHODS}

This study was conducted among the $1^{\text {st }}$ and $2^{\text {nd }}$ year female undergraduate students of Jawaharlal Nehru Institute of Medical Sciences, Imphal. A stratified random sample method was used. The sample size was calculated by the following formula:

$\mathrm{n}=\left(\mathrm{Z}^{2} \times \mathrm{p} \times \mathrm{q}\right) / \mathrm{E}^{2}$

Where, $\mathrm{n}=$ the sample size, $\mathrm{Z}=1.96, \mathrm{p}=20 \%=0.2, \mathrm{q}=1-\mathrm{p}=$ $0.8, \mathrm{E}=7.2 \%$. Therefore, $\mathrm{n}=118.567$ by using finite population correction factor, $\mathrm{n}=80.643=81$ approx.

This study included 81 female students aged 18-22 years with previous normal cycles. Students with any medical/surgical or endocrine condition, on any drugs or hormone treatment or previous abnormal cycles were excluded.

Written consent was taken from the participants after clearance from the Ethical Committee of the Institute. They were given verbal explanations about the topic and the aim of the study. A questionnaire along with the IMPS was provided to them. The questionnaire dealt with anthropometric data, menstrual history and menstrual health status.

IMPS was developed for use in assessing distress by measuring the amount of stress response such as physical, psychological and behaviour changes which a person under psychosocial stress experiences (11). The subjects were asked to choose their answer from each of the 40 items of the IMPS from one of: "yes", "rather yes", "rather no" and "no". "No" and "rather no" were multiplied by zero, "rather yes" by one and "yes" by two. The score was calculated by adding all of the numbers together, ranging from zero to eighty. We refer to the score measured using the IMPS as the stress score in this study.
The menstrual cycle was defined as the period between the first day of menstrual flow and the day immediately prior to the next menstrual flow. Heavy menstrual flow was based on a self-rated assessment of the volume of bleeding during menses. Premenstrual symptoms were defined as a constellation of physical, emotional, and behavioural symptoms which occur premenstrually and remit after the onset of bleeding and included abdominal pain, headache, nausea, abdominal bloating, painful breast, irritability, anger, depression, increased food intake, decreased food intake, hypersomnia and lack of energy.

Menstrual pain was defined as acute spasmodic pain (Menstrual cramps), commonly experienced in the lower abdomen, which appears on the first day of menses and rarely lasts for more than 2 days. The experience of irregular menstrual cycles was defined as a past history of irregular menstrual cycles experienced by the students up to the time of the study. Such cycles included amenorrhea (Menses occurring less often than every three months), long cycles ( $\geq 39$ days) for two consecutive periods or more, short cycles ( $\leq 24$ days) for two consecutive periods or more, and menstrual cycles too irregular to determine the cycle length.

\section{Statistical Analysis}

The data was analysed using Statistical Package for the Social Sciences (SPSS) version 22. Unpaired t-tests were used to test for differences in the means of IMPS- measured stress scores between students who had premenstrual symptoms, menstrual pain, or the experience of irregular menstrual cycles and those who did not. The $\mathrm{x}^{2}$ test was used to explore the linear relationship between premenstrual symptoms, menstrual pain, and the experience of irregular menstrual cycles and stress score or body mass index (BMI). All the values were expressed as mean $( \pm \mathrm{SD})$ and $p$ less than 0.05 was taken as significant.

Binary logistic regression model was used in our study to estimate odds ratio and $95 \%$ confidence intervals of premenstrual symptoms, menstrual pain, and the experience of irregular menstrual cycles with psychosocial stress score, while adjusting for age at menarche, BMI, heavy menstrual flow, menstrual cycle length and duration of menstrual flow.

\section{RESULTS}

\begin{tabular}{|c|c|c|c|}
\hline Characteristics & Mean (S.D.) & Minimum & Maximum \\
\hline Age (year) & $20.23( \pm 1.154)$ & 18 & 24 \\
\hline Height $(\mathrm{cm})$ & $155.16( \pm 5.214)$ & 142 & 175 \\
\hline Weight $(\mathrm{Kg})$ & $48.23( \pm 5.789)$ & 36 & 65 \\
\hline BMI $\left(\mathrm{Kg} / \mathrm{m}^{2}\right)$ & $20.01( \pm 2.1981)$ & 16 & 27 \\
\hline Stress Score & $20.60( \pm 6.888)$ & 10 & 35 \\
\hline $\begin{array}{c}\text { Age at menarche } \\
\text { (year) }\end{array}$ & $12.94( \pm 1.017)$ & 11 & 16 \\
\hline
\end{tabular}

Table 1. The Mean ( \pm Standard Deviation) Values of Demographic Data, Stress Score and Age at Menarche

\section{S.D. indicates Standard deviation.}

The mean $( \pm S D)$ values of demographic data, stress score and age at menarche are shown in table 1 . The mean age of 81 students was 20.23 ( \pm 1.154 ) years ranging from 18 to 24 years. The average height and weight were $155.16( \pm 5.214)$ $\mathrm{cm}$ and 48.23 ( \pm 5.789$) \mathrm{Kg}$ respectively. The mean body mass 
index (BMI) was $20.01( \pm 2.198) \mathrm{Kg} / \mathrm{m}^{2}$. The mean value of stress score was $20.60( \pm 6.888)$ ranging from 10 to 35 . The average age at menarche was $12.94( \pm 1.017)$ years ranging from 11 to 16 years.

\begin{tabular}{|c|c|c|}
\hline Characteristics & No. of Frequency & Percentage \\
\hline \multicolumn{3}{|c|}{ Stress score } \\
\hline $0-9$ & Nil & Nil \\
\hline $10-19$ & 30 & $47 \%$ \\
\hline $20-39$ & 43 & $53 \%$ \\
\hline $40-80$ & Nil & Nil \\
\hline \multicolumn{3}{|c|}{ Premenstrual Symptoms } \\
\hline Yes & 65 & $80 \%$ \\
\hline No Menstrual Cycle Length \\
\hline$\leq 24$ days & 34 & $42 \%$ \\
\hline $25-28$ days & 27 & $33 \%$ \\
\hline$\geq 39$ days & 20 & $25 \%$ \\
\hline \multicolumn{2}{|c|}{ Duration of Menstrual Flow } \\
\hline 32 days & 7 & $9 \%$ \\
\hline$\geq 38$ days & 72 & $89 \%$ \\
\hline \multicolumn{2}{|c|}{2} \\
\hline
\end{tabular}

\begin{tabular}{|c|c|c|}
\hline \multicolumn{3}{|c|}{ Heavy Menstrual Flow } \\
\hline Passage of blood clot & 50 & $62 \%$ \\
\hline Using not less than 4-5 pads & 31 & $38 \%$ \\
\hline \multicolumn{3}{|c|}{ Menstrual Pain } \\
\hline Yes & 65 & $80 \%$ \\
\hline No & 16 & $20 \%$ \\
\hline Irregular Menstrual Cycle \\
\hline Yes & 54 & $67 \%$ \\
\hline Noble 2. The Percentage of Categories \\
of Stress Score and Menstrual Data \\
\hline
\end{tabular}

The percentage of categories of stress score and menstrual data are given in table 2. Fifty-three percent (53\%) of students have stress score ranging from 20-39 while $47 \%$ have stress score 10-19. Most students (80\%) reported premenstrual symptoms. The proportion of students who reported irregular menstrual cycles and heavy menstrual flow were $67 \%$ and $62 \%$ respectively. Most of the students have normal duration of menstrual flow (89\%). Thirty-three percent have normal menstrual cycle length while $42 \%$ and $25 \%$ of students have short and long menstrual cycle length respectively. Most of the students (80\%) also reported menstrual pain.

\begin{tabular}{|c|c|c|c|c|c|}
\hline & n (Yes/No) & Stress Score Mean (S.D.) & t & df & P \\
\hline Premenstrual symptoms & $65 / 16$ & $20.95( \pm 7.2) / 19.19( \pm 5.4)$ & 25.98 & 80 & .001 \\
\hline Menstrual Pain & $65 / 16$ & $21.54( \pm 6.8) / 19.10( \pm 6.9)$ & 25.98 & 80 & .001 \\
\hline Irregular menstrual cycle & $54 / 27$ & $20.78( \pm 6.9) / 20.26( \pm 6.8)$ & 26.05 & 80 & .001 \\
\hline \\
Table 3. The Relationship between Premenstrual Symptoms, Menstrual \\
Pain and Irregularity of Menstrual Cycle with Stress Score
\end{tabular}

S.D. indicates standard deviation; $\mathrm{df}$, degree of freedom.

The relationship between premenstrual symptoms, menstrual pain and irregular menstrual cycle with stress score are shown in table 3. The students who have premenstrual symptoms have a significantly higher stress score than those who do not ( $\mathrm{p}<$ 0.001). Those students who reported menstrual pain $(\mathrm{p}<0.001)$ and irregular menstrual cycle $(\mathrm{p}<0.001)$ also have a significantly higher stress score than those who did not.

\begin{tabular}{|c|c|c|c|c|}
\hline & \multirow{2}{*}{ Variables } & \multirow{2}{*}{ aOR } & \multicolumn{2}{|c|}{ 95\%CI } \\
\hline & & & Lower & Upper \\
\hline \multirow{6}{*}{ Premenstrual symptoms } & Age at menarche & 0.539 & 0.281 & 1.034 \\
\hline & BMI & 1.002 & 0.769 & 1.305 \\
\hline & Stress Score & 1.062 & 0.973 & $1.159^{* *}$ \\
\hline & Heavy menstrual flow & 1.513 & 0.444 & 5.154 \\
\hline & Menstrual cycle length & 0.731 & 0.352 & 1.521 \\
\hline & Duration of menstrual flow & 2.357 & 0.409 & 13.574 \\
\hline \multirow{6}{*}{ Menstrual pain } & Age at menarche & 0.717 & 0.419 & 1.225 \\
\hline & BMI & 1.205 & 0.940 & 1.547 \\
\hline & Stress Score & 1.038 & 0.963 & $1.119^{* *}$ \\
\hline & Heavy menstrual flow & 2.204 & 1.728 & 6.677 \\
\hline & Menstrual cycle length & 0.670 & 0.352 & 1.278 \\
\hline & Duration of menstrual flow & 0.314 & 0.045 & 2.187 \\
\hline \multirow{6}{*}{ Irregular menstrual cycle } & Age at menarche & 0.715 & 0.428 & 1.207 \\
\hline & BMI & 1.188 & 0.935 & $1.508^{*}$ \\
\hline & Stress Score & 1.028 & 0.957 & $1.104^{* *}$ \\
\hline & Heavy menstrual flow & 1.995 & 0.683 & 5.829 \\
\hline & Menstrual cycle length & 0.693 & 0.373 & 1.285 \\
\hline & Duration of menstrual flow & 2.118 & 0.447 & 10.038 \\
\hline Menst & $\begin{array}{l}\text { Probability of having Pr } \\
\text { erience of Irregular Cycle }\end{array}$ & $\begin{array}{l}\text { Sympt } \\
\text { Studer }\end{array}$ & & \\
\hline
\end{tabular}

aOR indicates adjusted odds ratio; $\mathrm{CI}$, confidence interval; $\mathrm{P}^{*}<0.05 ; \mathrm{p}^{* *}<0.001$; adjusted for age at menarche, BMI (body mass index), heavy menstrual flow, menstrual cycle length and duration of menstrual flow. 
Logistic regression analysis with stress score is shown in table 3. Stress score was found to be a significant predictor for having premenstrual symptoms $(\mathrm{OR}=1.06,95 \% \mathrm{CI}=0.9$ $1.2, \mathrm{p}=0.001)$ and menstrual pain $(\mathrm{OR}=1.04,95 \% \mathrm{CI}=0.9-1.1$, $\mathrm{p}=0.001)$. Both BMI $(\mathrm{OR}=1.18,95 \% \mathrm{CI}=0.9-1.2, \mathrm{p}=0.01)$ and stress score $(\mathrm{OR}=1.02,95 \% \mathrm{CI}=0.9-1.1, \mathrm{p}=001)$ were found to be predictors for experiencing irregular menstrual cycle

Figure 1: Relatiom between the stress score and proportion of students who had premenstrual symptoms, menstrual pain and irregular menstrual cycle

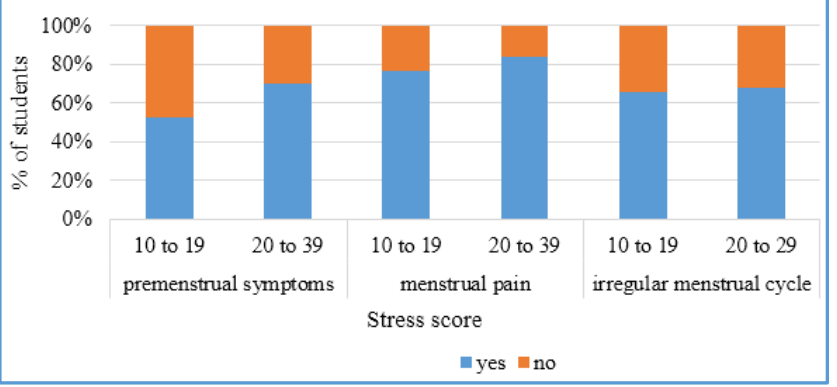

Figure 1 shows the relationship between stress score and the proportion of students who had premenstrual symptoms. The higher a student's stress score becomes, the more likely it was that the student had premenstrual symptoms $\left(x^{2}=5.869\right.$, df (degree of freedom $\left.)=1, p=0.015\right)$. Similarly, the higher a student's stress score, the more likely it was that the student had menstrual pain $\left(\mathrm{x}^{2}=17.332, \mathrm{df}=1, \mathrm{p}=0.001\right)$ and irregular menstrual cycle $\left(x^{2}=21.314, d f=1, p=0.001\right)$.

\section{DISCUSSION}

This study was conducted to examine whether there is any relationship between IMPS-measured stress score and menstrual function-related abnormalities like premenstrual symptoms, menstrual pain and irregular menstrual cycle among the female undergraduate medical students. In the present study, it is found that those students who experience premenstrual symptoms, menstrual pain and irregular menstrual cycle have higher value of stress score than those who do not (Table 3). These findings are consistent with a study done by Singh et al ${ }^{10}$ which reported a significant association of increased stress scores with menstrual pain, premenstrual symptoms and passage of clots among the medical students. Their study has also demonstrated a significantly positive association of stress with premenstrual symptoms as well as decreased flow. Similarly, a study done among the Japanese college students showed higher stress score among students reporting menstrual function-related abnormalities than those who did not. ${ }^{12}$

A contrary result was observed by Sood et al in the study conducted among the female medical students from first and second year. ${ }^{11}$ They found that there is no significant association between psychological stress level and menstrual abnormalities. Another study conducted by Clarvit et al 13 reported no association between perceived stress and menstrual problems.

The present study reveals stress score as a predictor for premenstrual symptoms and irregular menstrual cycle (table 4). Stress level as a predictor of premenstrual symptoms and irregular menstrual cycle in the Japanese college students has been reported. ${ }^{12}$ It is suggested from the earlier studies how stress can affect woman's menstrual cycle. ${ }^{14}$ Stress causes activation of hypothalamic-pituitary-adrenal (HPA) axis which inhibits hypothalamic-pituitary-gonadal axis, ${ }^{15}$ thereby increasing the level of Corticotrophin releasing hormone $(\mathrm{CRH})$ and cortisol. ${ }^{16}$ Cortisol increases brain function and slows or stops other non-essential body functions such as digestion and reproduction. ${ }^{17}$ Consequently, the synthesis and metabolism of gonadotropins and oestrogen are suppressed, ${ }^{14}$ thereby disrupting the woman's menstrual function. Ekpenyong et $\mathrm{al}^{9}$ reported that those who reported a high level of academic stress had about 2 times likelihood of having menstrual disorders than those without academic stress.

The present study also shows stress as a predictor for experiencing menstrual pain. Similar to our findings study on female medical students showed stress as a predictor of dysmenorrhoea. ${ }^{18}$ It is believed that stress causes activation of hypothalamic-pituitary-adrenal (HPA) axis which inhibits hypothalamic-pituitary-gonadal axis resulting in the inhibition of pulsatile release of Follicular stimulating hormone (FSH) and Luteinizing hormone (LH). ${ }^{17}$

Consequently, there is stress-induced impairment of follicular development which alters progesterone synthesis and release. This reduces synthesis and binding of prostaglandins (PGF2 and PGE2) to myometrial receptors. ${ }^{19}$ Prostaglandins affect uterine muscles and vascular tone. Therefore, an imbalance of prostaglandins have been linked to the occurrence of dysmenorrhea. Also, stress-related hormones, adrenaline and cortisol seem to affect prostaglandin synthesis and vasopressin with a consequent effect on myometrium. ${ }^{20}$

\section{Limitations}

The study has some limitations. First of all the sample size is small. Secondly, as the IMPS-measured stress scores were self-reported by students, it may have resulted in some reporting bias. Lastly, evaluation of premenstrual symptoms, menstrual pain and irregular menstrual cycles were not based on biomedical markers or hormones measurement, but solely on self-report of the students' subjective perception and recognition.

\section{CONCLUSION}

The findings of the present study showed that there is a relationship between stress measured by IMPS and menstrual cycle-related problems. Also, this study reveals stress as a predictor of premenstrual symptoms, menstrual pain and irregular menstrual cycle.

\section{ACKNOWLEDGEMENTS}

We would like to thank all $1^{\text {st }}$ and $2^{\text {nd }}$ year medical students of JNIMS, Imphal, who participated in our study.

\section{REFERENCES}

[1] Yamamoto K, Irie M, Sakamoto $Y$, et al. The relationship between IMPS-measured stress score and biomedical parameters regarding health status among public school workers. J Physiol Anthropol 2007;26(2):149-58.

[2] Misra R, McKean M. College students' academic stress and its relation to their anxiety, time management and leisure satisfaction. Am J Health Studies 2000;16(1):41-51. 
[3] Abouserie R. Sources and levels of stress in relation to locus of control and self-esteem in university students. Educational Psychology 1994;14(3):323-30.

[4] Zaid ZA, Chan SC, Ho JJ. Emotional disorders among medical students in a Malaysian private medical school. Singapore medical journal 2007;48(10):895-9.

[5] Kunwar D, Risal A, Koirala S. Study of depression, anxiety and stress among the medical students in two medical colleges of Nepal. Kathmandu Univ Med J 2016;14(53):22-6.

[6] Iqbal S, Gupta S, Venkatarao E. Stress, anxiety \& depression among medical undergraduate students \& their socio-demographic correlates. Indian J Med Res 2015;141(3):354-7.

[7] Nohara M, Momoeda M, Kubota T, et al. Menstrual cycle and menstrual pain problems and related risk factors among Japanese female workers. Ind Health 2011;49(2):228-34.

[8] Harlow SD, Matanoski GM. The association between weight, physical activity, and stress and variation in the length of the menstrual cycle. Am J Epidemiol 1991;133(1):38-49.

[9] Ekpenyong CE, Davis KJ, Akpan UP, et al. Academic stress and menstrual disorders among female undergraduates in Uyo, South Eastern Nigeria - the need for health education. Niger J Physiol Sci 2011;26(2):193-8.

[10] Singh R, Sharma R, Rajani H. Impact of stress on menstrual cycle: a comparison between medical and non medical students. Saudi J Health Sci 2015;4(2):115-9.

[11] Sood M, Devi A, Azlinawati, et al. Menses and stress related changes in female medical students. Procedia Social and Behavioral Sciences 2012;36:123-7.
[12] Yamamoto K, Okazaki A, Sakamoto $Y$, et al. The relationship between premenstrual symptoms, menstrual pain, irregular menstrual cycles, and psychosocial stress among Japanese college students. J Physiol Anthropol 2009;28(3):129-36.

[13] Clarvit SR. Stress and menstrual dysfunction in medical students. Psychosomatics 1988;29(4):404-9.

[14] Tsigos C, Chrousos GP. Hypothalamic-pituitaryadrenal axis, neuroendocrine factors and stress. J Psychosom Res 2002;53(4):865-71.

[15] Nepomnaschy PA, Sheiner E, Mastorakos G, et al. Stress, immune function, and women's reproduction. Ann N Y Acad Sci 2007;1113:350-64.

[16] Zhou M, Wege N, Gu H, et al. Work and family stress is associated with menstrual disorders but not with fibrocystic changes: cross-sectional findings in Chinese working women. J Occup Health 2010;52(6):361-6.

[17] Kalantaridou SN, Makrigiannakis A, Zoumakis E, et al. Stress and the female reproductive system. J Reprod Immunol 2004;62(1-2):61-8.

[18] Ibrahim NK, AlGhamdi MS, Al-Shaibani AN, et al. Dysmenorrhea among female medical students in king Abdulaziz university: prevalence, predictors and outcome. Pak J Med Sci 2015;31(6):1312-7.

[19] Ylikorkala O, Dawood MY. New concepts in dysmenorrhea. Am J Obstet Gynecol 1978;130(7):83347.

[20] Liedman R, Hansson SR, Howe D, et al. Reproductive hormones in plasma over the menstrual cycle in primary dysmenorrhea compared with healthy subjects. Gynecol Endocrinol 2008;24(9):508-13. 